\title{
TRANSMISSÃO DE SINAL DE CELULAR PARA ÁREAS RURAIS
}

\author{
TRANSMISSION OF SIGNAL OF CELL FOR RURAL AREAS
}

ISSN: 1984-3151

\author{
Alan Patrick Ferreira Lourenço'; Fabiana Danielle Alvez da Cruz²; Junia Taize Santos \\ Roberto Compart ${ }^{3}$;
}

1 Engenheiro Eletricista. Centro Universitário de Belo Horizonte - UniBH. Açoforja indústria de forjados S.A. Belo Horizonte, MG. - alanplourenco@ig.com.br,

2 Engenheira Eletricista. Centro Universitário de Belo Horizonte - UniBH. Comau do Brasil - Belo Horizonte, MG. - fabianaalves23@gmail.com.

3 Mestre em Eletromagnetismo Computacional, UFMG, 2007. Centro Universitário de Belo Horizonte - UNIBH, Belo Horizonte, MG - juniataize@hotmail.com.

Recebido em: 30/11/2011 - Aprovado em: 20/12/2011 - Disponibilizado em: 30/12/2011

RESUMO: O trabalho consiste em estudos de antenas e equipamentos para áreas rurais ou de difícil acesso, sem a disponibilidade da tecnologia de sinal de telefonia celular, com o objetivo de amenizar a comunicação entre as pessoas permitindo acesso às tecnologias avançadas do mundo atual e proporcionando melhores qualidades de vida para as pessoas das comunidades rurais. Assim o trabalho demonstra o desenvolvido de um equipamento capaz de captar, amplificar e retransmitir sinais de telefonia celular, com alta eficiência de funcionamento com baixo custo. No desenvolvimento do trabalho várias pesquisas são apresentadas, onde se inclui uma análise local, a qual se realiza um levantamento geral dos principais parâmetros da área de estudo, e a partir dos resultados obtidos proporcionou o desenvolvimento do protótipo do equipamento, além de demonstrar as principais características dos produtos, os quais foram especificados no trabalho, para composição das partes do equipamento.

PalavRas-Chave: Sistemas de telefonia. Telefonia Móvel Rural. Antenas. Serra do Cipó/MG. Amplificadores RF.

ABSTRACT: The work consists of studies of antennas and equipment for rural areas or difficult to access, without the availability of technology cell phone signal in order to ease communication between allowing people access to advanced technologies of today's world and providing better quality of life for people in rural communities. Thus this work demonstrates the development of a device able to capture, amplify and relay signals from cell phones, with high efficiency and lowest operating costs possible. In developing this work presents several research which includes a site analysis, which takes place a general survey of the main parameters of the study area, and from the results obtained enabled the development of the prototype equipment, and demonstrate the main features products, which were specified in the work, the composition of pieces of equipment.

KEYWORDS: Phone Systems. Rural Mobile. Antennas. Serra do Cipó / MG. RF amplifiers

\section{INTRODUÇÃo}

Desde o inicio dos tempos, vários pesquisadores estudam métodos para facilitar as comunicações entre as pessoas. Heinrich Hertz, em 1888, foi pioneiro da transmissão de códigos pelo ar. A descoberta tornouse primordial na implementação de rádiostransmissores. 
A comunicação móvel era conhecida desde o começo do século XX. Desenvolvido em 1940, o celular surge como um sistema de comunicação a distância que muda sempre de canal para que as freqüências não sejam interceptadas. No ano de 1947, no laboratório Bell, foi desenvolvido um sistema telefônico de alta capacidade interligado por diversas antenas, sendo que, cada antena, era considerada uma célula. Por isso o nome de "celular".

Mesmo sendo o sexto maior mercado do mundo e obtendo 202,94 milhões de aparelhos celular em uso, - Brasil ainda possui algumas deficiências em seu sistema de distribuição de sinais de telefonia móvel dentro de seu território. Normalmente estes sinais são somente disponibilizados para grandes centros urbanos, onde áreas rurais e ou com menores habitantes ainda não tem acesso a este sistema.

Uma região em especifico, que vem sofrendo com este problema é a região da Serra do Cipó/MG. Esta região é composta de várias diversidades ecológicas como serras, matas, rios e pedreiras e entre meios estas diversidades contém alguns vilarejos habitados por poucos habitantes (aproximadamente 100 pessoas cada um) e que não têm nenhum acesso à comunicação telefônica (fixa e móvel).

Assim verificou a necessidade de disponibilizar o acesso à telefonia móvel a estas pessoas, para suas necessidades pessoais e como questão de segurança. Desta forma iniciaram-se estudos sobre a região, o qual foi diagnosticada a necessidade de criar um equipamento similar aos das operadoras de telefonia celular, de baixo custo e que seja capaz de captar, amplificar e retransmitir sinais de celular, para atender a esta região e outras regiões que ainda não tem acesso à telefonia celular.

Portanto, o trabalho se justifica pela necessidade de facilitar a comunicação entre as pessoas e permitir acesso às tecnologias avançadas do mundo atual, visando a melhoria de qualidade de vida das comunidades rurais. Com isso, são gerados benefícios às empresas de telefonia celular, ao proporcionar um maior número de usuários ao sistema. Além disso, contribui para a ampliação de informações, gerando novos dados referentes ao assunto, acrescentando, assim, conhecimentos para comunidade científica e aos pesquisadores.

\section{REFERENCIAIS TEÓRICOS}

\subsection{O TRANSPORTE DA INFORMAÇÃO}

Segundo Barradas (1995) a informação deve ser transportada da fonte ao destinatário, este tipo de transporte normalmente efetuado pelos canais de transmissões. Os canais de transmissões são o conjunto de dispositivos que transmite (TX), captura $(R X)$ sinais e o meio de transporte destas informações, (Figura 1).

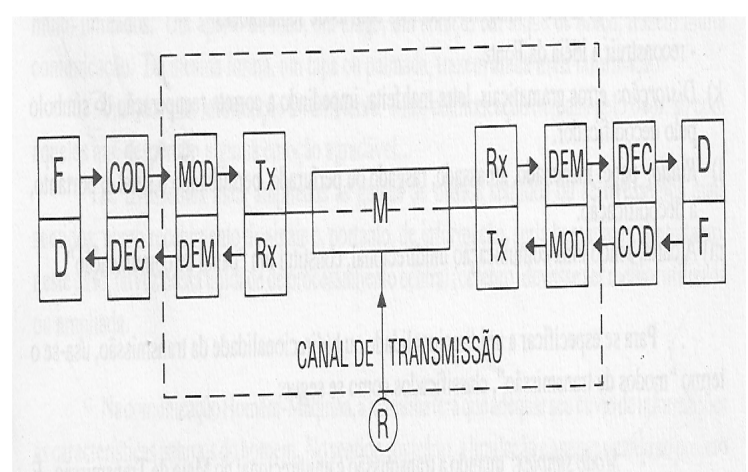

Figura 1 - Canal de transmissão de telefonia Fonte: BARRADAS, 1995, p.17.

Em outras palavras os canais de transmissões são compostos pelo meio de transmissão, pelos transceptores e pelos modens (BARRADAS, 1995).

\subsubsection{OS MEIOS DE TRANSMISSÕES}

Segundo Barradas (1995) o transporte da informação a distância é realizado pelo meio de transmissão. Para 
todos os sistemas de telecomunicações existem apenas três meios distintos, cada um admitindo certo tipo de energia possível de ser transmitida. Fios metálicos: portadora em CC ou CA (corrente elétrica). Espaço: portadora em CA (onda eletromagnética), Fibra óptica: portadora em luz (onda eletromagnética). Uma vez que o estudo está direcionado ao sistema de telefonia móvel celular, será dada ênfase somente os sistemas de transmissões no espaço (BARRADAS, 1995).

\subsubsection{O ESPAÇO}

Segundo Barradas (1995) os principais parâmetros de uma onda que se propaga no espaço são as frequências (f), o período (T), e o comprimento $(\lambda)$, este dados são importantíssimos para dimensionamentos de antenas, entendimento de mecanismos de irradiação e propagações. As energias transmitidas no espaço sofrem atenuações conforme as distâncias e as barreiras existentes no local.

O mesmo autor afirma que o mecanismo de propagação de ondas é definido conforme sua freqüência no espaço. Os sistemas que utilizam frequências baixas transmitem estas ondas e suas partes inferiores se arrastam sobre a superfície da Terra e se inclinam um pouco deformando a sua forma esférica, suas partes superiores se expandem ao espaço aonde chegam à ionosfera e são refletidas de volta a terra. Estas ondas refletidas são conhecidas como ondas celestes (Figura 2).

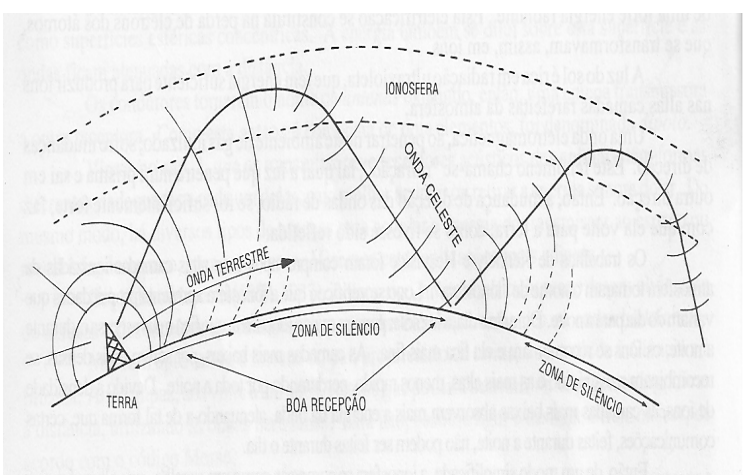

Figura 2 - Transmissão em baixas freqüências Fonte: BARRADAS, 1995, p.42

Ainda o mesmo autor afirma que em altas frequências, a onda contém a capacidade de transportar maiores números de dados em alta velocidade, mas sofrem mais facilmente interferências do seu meio. Um exemplo de sistemas de alta freqüência é a microondas, estas trabalham na faixa de $300 \mathrm{MHZ}$ a $300 \mathrm{GHZ}$, neste sistema utilizam antenas de transmissão e recepção para se evitar que haja muitos obstáculos entre as comunicações. O mecanismo de propagação destas ondas pode ser focalizado e estas se propagam tangencialmente à terra. Neste caso a ionosfera se torna mais transparente e ao invés de refletir a onda, ela simplesmente provoca uma distorção em sua direção (Figura 3).

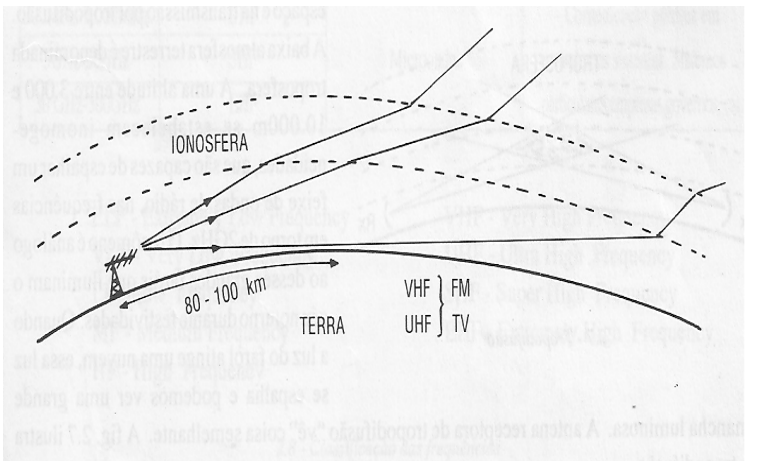

Figura 3 - Transmissão em altas freqüências Fonte: BARRADAS, 1995, p.43. 
Tabela 1 - Classificação das Freqüências ALOCAÇÃO DE FREQUÊNCIAS

\begin{tabular}{|c|c|c|c|}
\hline FAIXA & DESIGNAÇÃO & NOME POPULAR & UTILIZAÇÃO \\
\hline $300 \mathrm{~Hz}-3.000 \mathrm{~Hz}$ & ELF & $\begin{array}{c}\text { Ondas extremamente } \\
\quad \text { longas }\end{array}$ & $\begin{array}{c}\text { Comunicaçóes } \\
\text { para submarinos, }\end{array}$ \\
\hline $3 \mathrm{kHz}-30 \mathrm{kHz}$ & VLF & Ondas muito longas & escavaçóes em minas, etc. \\
\hline $30 \mathrm{kHz}-300 \mathrm{kHz}$ & LF & Ondas longas & $\begin{array}{l}\text { Auxílio à navegação aérea } \\
\text { serviços marítimos, }\end{array}$ \\
\hline $300 \mathrm{kHz}-3.000 \mathrm{kHz}$ & MF & Ondas médias & radiodifusāa local \\
\hline 3MHz-30MHz & $\mathrm{HF}$ & $\begin{array}{l}\text { Ondas tropicais } \\
\text { Ondas curtas }\end{array}$ & $\begin{array}{c}\text { Radiodifusão local e distante, } \\
\text { comunicaçōes marítimas }\end{array}$ \\
\hline 30MHz-300MHz & VHF & - & $\begin{array}{l}\text { TV-FM-Comunicaçōes } \\
\text { comerciais,particulares, seguranç̧a } \\
\text { pública,faixa do cidadāo, } \\
\text { radioamadores, etc. }\end{array}$ \\
\hline $300 \mathrm{MHz}-3.000 \mathrm{MHz}$ & UHF & \multirow{3}{*}{ Microondas } & \multirow{3}{*}{$\begin{array}{c}\text { Comunicação pública em } \\
\text { todos os sistemas. Sistemas } \\
\text { particulares, mpresas, governos, etc. }\end{array}$} \\
\hline $3 \mathrm{GHz}-30 \mathrm{GHz}$ & SHF & & \\
\hline $30 \mathrm{GHz}-300 \mathrm{GHz}$ & EHF & & \\
\hline
\end{tabular}

$$
\begin{array}{ll}
\text { ELF - Extremely Low Frequency } & \text { VHF - Very High Frequency } \\
\text { VLF - Very Low Frequency } & \text { UHF - Ultra High Frequency } \\
\text { LF - Low Frequency } & \text { SHF - Super High Frequency } \\
\text { MF - Medium Frequency } & \text { EHF - Extremely High Frequency }
\end{array}
$$

HF - High Frequency

Fonte: BARRADAS, 1995, p.45.

Segundo Barradas (1995) no estudo do espaço como meio de transmissão é necessário conhecer bem os serviços de telecomunicações a serem executados, as frequências possíveis de serem utilizadas, as condições de ionosférica, o tipo de transmissor e os tipos de antenas a ser utilizadas (Tabela 1).

\subsection{ANTENAS}

Kraus (1983) afirma que a antena pode ser definida como uma estrutura associada com a região de transmissão entre uma onda guiada e uma onda no espaço livre, ou vice-versa, (Figura 4).

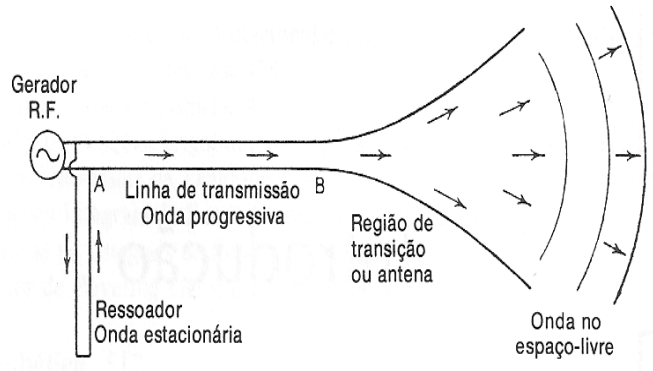

Figura 4 - A antena

Fonte: KRAUS, 1983, p.2.
O mesmo autor diz que as antenas têm a função de transformar energia eletromagnética guiada pela linha de transmissão em energia eletromagnética irradiada, pode-se também dizer que esta lei serve também no sentido inverso. Portanto, sua função é primordial em qualquer comunicação onde exista radiofrequência. $E$ ainda afirma o mesmo autor, que no estudo e projeto de antenas, não importa em que frequência do espectro seja aplicada, sempre serão usados os mesmos princípios físicos da teoria eletromagnética, ela é constante, imutável e invariável. Por isso, quanto maior a frequência de utilização nas antenas, maior deve ser a precisão dos dispositivos, equipamentos e medições.

Existem vários tipos de antenas, cada uma contendo suas características e suas aplicações. Os principais parâmetros a ser verificado nas antenas são suas potências, seus ganhos e atenuações, sua intensidade de irradiação, suas impedâncias e suas dimensões para determinar as freqüências na qual esta irá transmitir e captar sinais (BALANIS, 2005).

\subsubsection{ANTENAS YAGI-UDA}

Gomes (2004) afirma que as antenas yagi-uda são compostas de um dipolo e outros elementos, que podem ser refletores ou diretores.

Segundo o mesmo autor, quando são inseridos outros elementos a uma antena, o sinal emitido é direcionado no sentido dos elementos menores e reduzido na direção em que está o elemento maior (Refletor). Na recepção ocorre o mesmo, isto é, o sinal provindo da frente (Diretor) é mais bem recebido que o que provém de trás (Refletor) da antena, a esse efeito é dada uma relação chamada relação frente-costa. As antenas Yagi, da mesma forma que as antenas dipolo, também podem ter polarização horizontal ou vertical, dependendo do fim para que se destine. 
A maioria das antenas yagi é coberta por um "tubo", que protege a antena das intempéries e melhora o aspecto visual, mas a antena propriamente dita tem um formato de espinha de peixe. É justamente este formato que permite que o sinal seja tão concentrado, estas oferecem um maior alcance, mas em compensação são capazes de cobrir apenas uma pequena área, para onde são apontadas. Estas antenas são mais úteis para cobrir alguma área específica, longe do ponto de acesso, ou interligar duas redes distantes (MORIMOTO, 2008).

\subsubsection{ANTENA PAINEL SETORIAL}

A antena painel setorial concentra o sinal em um ângulo de aproximadamente 90 graus, ou seja, um quarto de um círculo completo. Se instaladas no canto de um galpão ou cômodo, elas distribuem o sinal em todo o ambiente, deixando pouco sinal vazar no outro sentido. As maiorias das antenas setoriais trabalham com ganho de 12 a $17 \mathrm{dBi}$. Embora no papel a diferença possa parecer pequena, uma antena de 17 $\mathrm{dBi}$ trabalha com uma potência de transmissão pouco mais de 3 vezes maior que uma de $12 \mathrm{dBi}$. Este tipo de antena atenua levemente os ruídos vindo de trás e sua atenuação quanto a ruídos laterais quase não existe (MORIMOTO, 2008).

\subsection{TELEFONIA MÓVEL}

Segundo Barradas (1995) a principal exigência da telefonia móvel é fazer a comunicação de qualquer assinante da rede pública existente no mundo com qualquer outro assinante móvel. O primeiro sistema a ser utilizado para atender esta exigência, dentro da mesma cidade, foram a da ERB (Estação Radio Base) com transceptores. Sabendo que as informações na telefonia são bilaterais e simultâneas, e que este tipo de sistema utiliza dois canais de voz em duas portadoras a FCC (Federal Communication Comission), fixou no EUA e no Brasil faixas de transmissão e recepção de sinais nas ERB.

- Transmissão: $824 \mathrm{MHZ}$ a $849 \mathrm{MHZ}$

- Recepção: 869MHZ a 894MHZ

O mesmo autor diz que desta forma um veículo, em comunicação, emite uma onda portadora dento da faixa de transmissão (TX) e recebe outra, dentro da faixa de recepção $(R X)$, as duas formando o circuito telefônico, Portanto, para atender a um grande número de veículos, é preciso um bom número de pares de portadoras. Desta forma as ERB devem ter vários transceptores que ficam situados, com antenas, em locais geográficos adequados, que dê o máximo de cobertura a certa região.

Segundo Bernal (2004), a CCC controla o processo de comutação de chamadas telefônicas, ou encaminhamento destas para outras centrais, inclusive para o da rede fixa telefônica. A CCC pode encaminhar chamadas para outras operadoras (ROAMING) e também é responsável pelo controle de todas as ERB's interligadas a ela por meios de enlaces implementados com rádios em microondas ou fibra óptica. Um dos processos a ser controlado é o hand-offs entre as ERB. A CCC também gera os dados referentes à cobrança pelo uso do sistema.

Segundo o mesmo autor numa mesma área de concessão, há tipicamente uma CCC para cada prestador de serviço de rede. A CCC controla a rede acessando banco de dados que contém todas as informações necessárias, como o banco que registra os usuários locais, aquela CCC (HLR). Esse banco de dados prove informação sobre todos os assinantes naquela área de operação local "HOME". 


\subsubsection{TeLEFONIA CELULAR MÓVEL}

Segundo Alencar (2001) uma determinada região ou área de cobertura geográfica a ser atendida pelo serviço móvel celular é dividida em sub-regiões que são chamados células.

Segundo o mesmo autor, a célula é área geográfica iluminada por uma estação rádio dentro da qual a recepção do sinal atende às especificações do sistema. Em sua concepção básica o sistema celular divide essa área em células de igual tamanho de tal forma que as estações rádio base (ERB) estejam localizadas no centro destas, trabalhando em frequências distintas, (Figura 5).

Segundo Barradas (1995), a telefonia celular móvel pode utilizar dois tipos de tecnologias distintas, a tecnologia analógica e a tecnologia digital.

Ainda o mesmo autor diz que o principal sistema analógico utilizado no Brasil é o AMPS (Advanced Móbile Celular Service) este sistema opera dentro da faixa alocada pela FCC (Federal Communication Commission - órgão regulador do governo americano) de $824 \mathrm{MHZ}$ a $849 \mathrm{MHZ}$ para TX e $869 \mathrm{MHZ}$ a $894 \mathrm{MHZ}$ para RX. (BARRADAS, 1995),

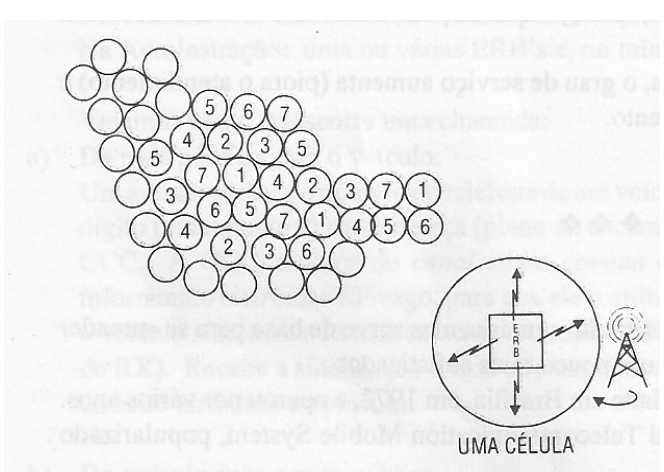

Figura 5 - Varias antenas irradiando (Fonte: BARRADAS, 1995 p.174).

Segundo Barradas (1995), no sistema analógico cada assinante ocupa um circuito de rádio freqência (RF) enquanto se comunica. Com o aumento de tráfego, logo o sistema chega ao congestionamento. Assim para resolver este problema foi criado pelo grupo de trabalho GMS (Groupe Speciale Móbiles) a tecnologia digital. Na tecnologia digital este grupo implantou o sistema TDM, no TDM o assinante além de disputar uma RF, também disputaria um tempo de canal, isso faria com que houvesse um aumento de número de assinantes sem aumentar as frequências do espectro. Logo após este mesmo grupo estabeleceu uma nova tecnologia, esta seria como a TDMA, esta recebeu o nome de GMS (Global System for mobílie Communication). Logo após para disputar com a tecnologia TDMA veio a CDMA (code division multiple access - acesso múltiplo por divisão de código). A idéia do CMDA é superpor sinais de 10 a 20 assinantes, em uma mesma portadora. Seus sinais seriam distinguidos por um código, impresso em cada um. Na recepção reconhecido um determinado código, o sinal correspondente é extraído da confusão dos 10 sinais que chegam.

\subsection{TeLEFONIA RURAL}

Segundo Barradas (1995), para implementar telefonia móvel em áreas rurais é necessário que haja pelo menos uma central de comutação manual ou automática, desta forma é necessario implantar nestas regiões uma CCC para controlar uma ou varias ERB's, que podem estar ou não no mesmo local. Com antenas diretivas focalizar os lugarejos ou fazendas distantes, abrindo-se rotas para eles. De forma que no usuário o sinal pode ser captado por uma antena, geralmente montada em uma torre. O cabo da antena termina no transceptor do usuário, ao qual está ligado um telefone.

O mesmo autor diz que a telefonia móvel rural no Brasil, ainda por maioria, é analógica, mas devido ao 
crescimento crescente do numero de CPA's de pequeno e médio porte, estão começado a ser implantado o sistema digital nestas regiões.

\section{Metodologia}

Segundo Gil (2010), esta é uma pesquisa experimental, do tipo estudo de caso, pois consiste em um estudo profundo e exaustivo de um ou poucos objetos, de maneira que permite seu amplo e detalhado conhecimento de tarefas praticamente impossíveis mediante outros delineamentos já considerados. Além disso, contém as características de explorar situações da vida real, cujos limites não estão claramente definidos, preserva o caráter unitário do objeto estudado, descreve a situação do contexto em que está sendo feita determinada investigação, formula hipóteses, desenvolve teorias e explica as variáveis causais de determinado fenômeno em situações muito complexas, que não possibilitam a utilização de levantamentos e experimentos.

O trabalho foi iniciado com realização de uma revisão bibliográfica, onde se utilizou vários livros e artigos, os quais se discutiam alguns assuntos considerados essenciais para o seu desenvolvimento. A partir da análise e do maior conhecimento destes assuntos foi possível a elaboração do equipamento.

Para inicialização do projeto foi executada uma análise, que teve como ponto de partida a verificação do posicionamento geográfico do local de estudo, no qual foi utilizado o programa de mapeamento geográfico o Google Earth, com o objetivo de determinar uma referência para análise e obtenção de dados referentes ao local. Logo após, utilizando recursos similares ao anterior, mas com um programa de análise de cobertura e sinal celular disponível na internet pela Anatel, foram identificadas as principais antenas de transmissões de dados da região, além de suas respectivas posições geográficas em relação à referência obtida na análise anterior.

Em seguida, foram determinadas as principais frequências de operação das operadoras de telefonia celular no local de estudo. Para isto, foram coletados dados nos sites das mesmas na página de roamings, onde é necessário identificar a região desejada para análise e assim o próprio site informa as frequências de operação de trabalho do local. Posteriormente, foi medida a intensidade do sinal que cobria a região ao qual se verificou a necessidade de instalação do equipamento e a intensidade do sinal que era disponibilizado pela antena mais próxima do local de estudo, com o objetivo de fazer uma análise comparativa dos resultados e assim desenvolver 0 protótipo do equipamento.

Para a coleta dos dados foram utilizados os equipamentos, Analisador de Espectro marca: Agilent Technologics, modelo: E5062A, Descrição: ATO$25396 / 300 \mathrm{kHz}$ a $3 \mathrm{GHz}$ em conjunto com 8 metros de cabo coaxial tipo RG213 e uma antena yagi-uda de 700MHz, modelo: SRY-HP, n. ${ }^{\circ}$ 0820. Estes equipamentos foram dispostos em dois pontos distintos na área de estudo, local de instalação do equipamento (ponto 1) e a 30 metros da torre da antena mais próxima do local de estudo (ponto 2), no município de Cardeal Mota, localizados na Serra do Cipó, em Santana do Riacho/MG, nos dias 17 e 18 de setembro de 2011. As coordenadas de localização dos pontos amostrados foram: Ponto 1 - Latitude = 19.281403 / longitude $=-43.621158$ e para o Ponto $2-$ Latitude $=-19.33667 /$ longitude $=-43.61806$.

O desenvolvimento do protótipo e a especificação dos materiais foram realizados conforme as necessidades do local, onde foram verificadas as principais características pré-dispostas, para cada equipamento, na análise de local. As cotações dos materiais foram realizadas a partir de pesquisas junto aos fabricantes, 
os quais foram levados em considerações à facilidade de aquisição do produto no mercado e sua viabilidade econômica.

A forma de instalação e os posicionamentos dos equipamentos determinados para o protótipo foram parametrizados, conforme especificações disponibilizadas nos manuais dos mesmos. Além da utilização de tutoriais expostos pela empresa Global Telecom na internet, (GLOBALTELECOM 2011), os quais discutem as principais características e os modos de instalação das antenas e dos aparelhos determinados no trabalho.

A analise de viabilidade econômica do equipamento foi executada a partir de várias pesquisas em diversos fornecedores, onde teve como objetivo principal reduzir ao máximo o custo do protótipo, mantendo a mesma eficiência do equipamento.

\subsection{CaracterizaÇÃo da ÁREA de EStudo}

O local estudo definido como a área modelo para desenvolvimento do protótipo está situado na região da Serra do Cipó, em Santana do Riacho/MG, no município de Cardeal Mota, em um lugarejo conhecido como usina, às margens do Rio Parauná (Figura 6).

Segundo SERRADOCIPO (2011), a área de estudo, região da Serra do Cipó se localiza a 100 quilômetros em direção nordeste de Belo Horizonte, logo depois da cidade de Lagoa Santa, na região sul da Cordilheira do Espinhaço, entre os paralelos 19 e $20^{\circ} \mathrm{S}$ e 43 e $44^{\circ} \mathrm{W}$, no divisor de águas das bacias hidrográficas dos rios São Francisco e Doce, sendo também divisora dos biomas Cerrado e Mata Atlântica, os dois mais ameaçados do país. As distâncias das principais cidades são: Belo Horizonte 100 km, São Paulo 681 km, Rio de Janeiro 532 km, Vitória 626 km, Brasília: $814 \mathrm{~km}$.

e-xacta, Belo Horizonte, v. 4, n. 3, p. 137-157. (2011). Editora UniBH. Disponível em: www.unibh.br/revistas/exacta/

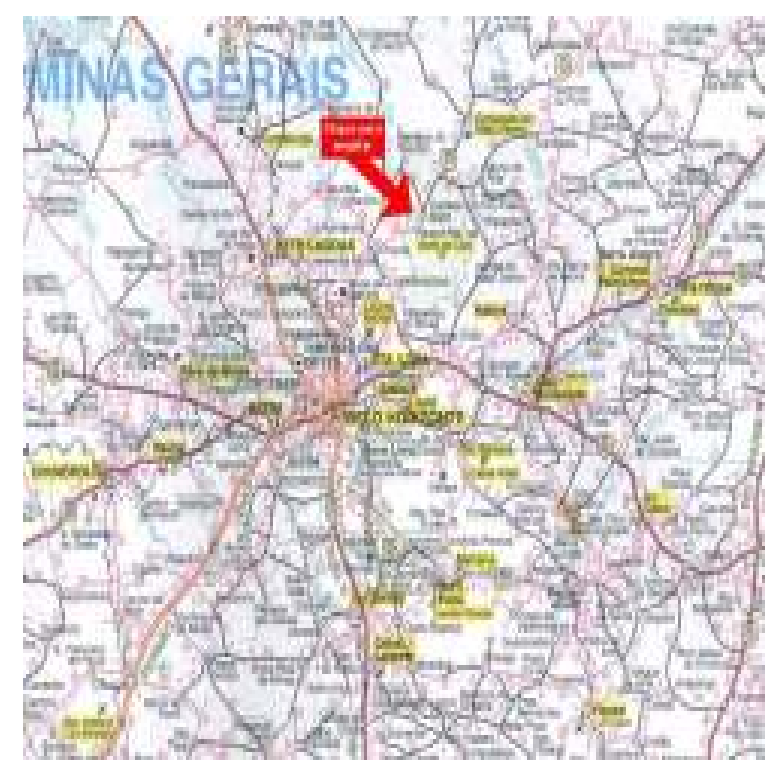

Figura 6 - Mapa de Localização Fonte: GUIASERRADOCIPO, 2011.

O local da instalação da antena está localizado aproximadamente $8 \mathrm{~km}$ da saída do quilometro $98 \mathrm{da}$ rodovia principal (Estrada real), dentro da Serra do Cipó, em uma propriedade particular do Sr. José Bruno, situado em uma região conhecida como Usina em um vilarejo cujo contém cerca de aproximadamente 100 habitantes.

\section{Resultados e discussão}

\subsection{ANÁLISE de LOCAL}

Os parâmetros de posicionamento do local a ser estudado foram especificados antes da checagem em campo, utilizando coordenadas obtidas diretamente do programa Google Earth, com o objetivo de instalar um equipamento capaz de captar amplificar e retransmitir sinais de telefonia celular.

Para a determinação dos parâmetros desejados no programa foi necessário especificar no mesmo o país, o estado, a cidade, o bairro e ruas do local, ondel é desejada a análise. Como a região estudada é uma 
área preservada, ela não contém bairros e nem ruas especificadas. Assim para especificação do local foram inseridos os seguintes dados, País: Brasil, Estado: Minas Gerais, Cidade: Santana do Riacho e para determinação precisa do local de estudo foi realizado uma inspeção visual e selecionado a área manualmente, o que possibilitou identificar os parâmetros do local com precisão. Os dados de posicionamento obtido através do programa para o local determinado para instalação da antena foram: Latitude $=-19.281403 /$ longitude $=-43.621158$, cuja altitude encontra-se a $750 \mathrm{~m}$ de altura em relação ao mar.

Para o desenvolvimento do protótipo foi necessário determinar quais os sinais, de onde originavam e a quais operadoras pertenciam, que eram captados com baixas intensidades, para a instalação do equipamento.

Assim utilizando referências disponibilizadas na internet pela Anatel, COBERTURACELULAR (2011), foi possível determinar o posicionamento das principais torres e as operadoras que disponibilizavam sinais para a região. Estas referências disponibilizadas pela Anatel consistem em um programa, no qual é necessário inserir os principais parâmetros do local a ser analisado, a latitude e a longitude, e o programa indica o posicionamento das torres e suas operadoras que se encontram mais próxima do local em análise, além de determinar o grau e as distâncias entre os dois pontos de estudo. (Tabela 2).

No mesmo programa, contém a opção de demonstrar os dados obtidos, anteriormente, de forma geográfica. Assim foi possível identificar no mapa de forma ilustrativa os posicionamentos indicados da (Tabela 2). Além do posicionamento do local onde deve ser instalado o equipamento projetado (Figura 7).
Tabela 2 - Posição das torres e suas operadoras

\begin{tabular}{|c|c|c|c|c|}
\hline Oper. & Lat. & Long. & $\begin{array}{l}\text { Alt. } \\
\text { (m) }\end{array}$ & $\begin{array}{l}\text { Dist. } \\
\text { (km) }\end{array}$ \\
\hline Oi & $-19,3367$ & $-43,6181$ & 817 & 6,154 \\
\hline Claro & $-19,3368$ & $-43,6181$ & 817 & 6,164 \\
\hline Tim & $-19,3372$ & $-43,63$ & 817 & 6,276 \\
\hline Vivo & $-19,3483$ & $-43,6183$ & 818 & 7,448 \\
\hline Claro & $-19,3811$ & $-43,6873$ & 814 & 13,079 \\
\hline Oi & $-19,1792$ & $-43,7161$ & 820 & 15,12 \\
\hline Oi & $-19,3367$ & $-43,7456$ & 810 & 29,676 \\
\hline Claro & $-19,5214$ & $-43,7457$ & 810 & 29,709 \\
\hline
\end{tabular}

Fonte: COBERTURACELULAR, 2011.

Outro parâmetro importante verificado na análise de local é a frequência de operação de trabalho nas quais as ERB's das operadoras disponibilizam sinal para cada região. Este parâmetro é importante, pois todos os equipamentos do projeto são especificados, conforme esta frequência de trabalho e, caso este parâmetro, seja ignorado, pode haver um comprometimento no funcionamento do equipamento, ocasionando baixa eficiência do produto.

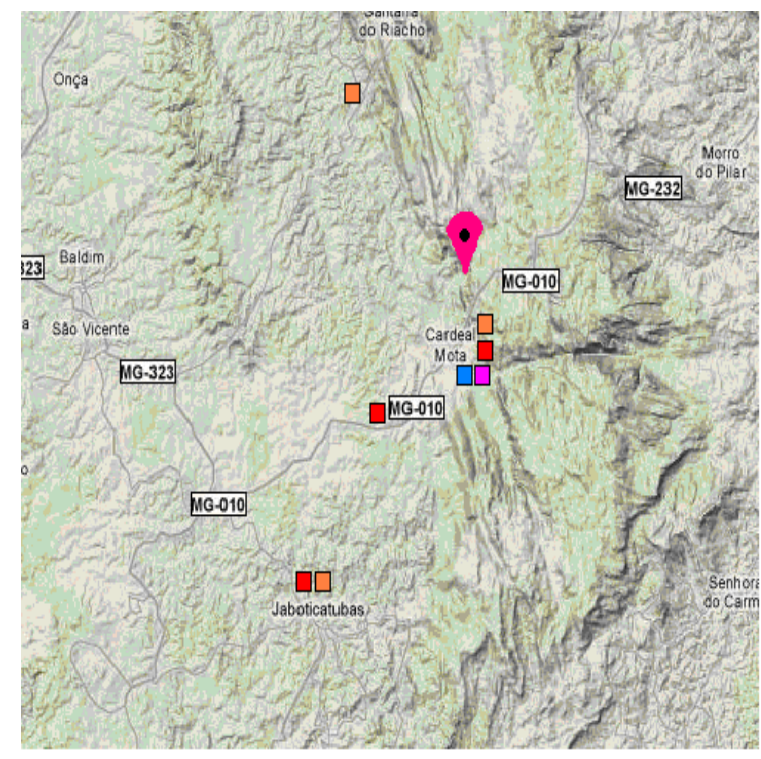

Figura 7 - Posicionamento geográfico das torres Fonte: COBERTURACELULAR, 2011. 
Assim, segundo informações adquiridas nos principais sites das operadoras de telefonias movéis do estado de Minas Gerais, as faixas de freqüências nas quais estas trabalham segue-se detalhado na (tabela 3 ), lembrando que como estas regiões estão fora dos grandes centros urbanos do estado, ainda não há a implementação do sistema 3G. Desta forma os sinais disponíveis para estes locais, em especifico a serra do cipó, são somente os sinais dos tipos GMS, GPRS e EDGE (Tabela 3).

Tabela 3 - Freqência de operação das operadoras

\begin{tabular}{|l|l|}
\hline OPERADORAS & Freqüência \\
\hline Claro & $1800 \mathrm{Mhz}$ \\
\hline Oi & $1800 \mathrm{Mhz}$ \\
\hline Vivo & $900 / 1800 \mathrm{Mhz}$ \\
\hline TIM & $1800 \mathrm{Mhz}$ \\
\hline
\end{tabular}

Fonte: OI, VIVO, CLARO, TIM, 2011.

Outro parâmetro bastante importante para o projeto do equipamento a ser desenvolvido é a verificação da potência de transmissão da antena fonte das operadoras. Assim, utilizando o analisador de espectro, mediu-se a intensidade do sinal irradiado pelas antenas das principais operadoras de telefonia celular do local (Tabela 4).

Tabela 4 - Intensidades dos sinais medidos das antenas fontes

\begin{tabular}{|c|c|}
\hline $\begin{array}{ll}\text { Freqüência } & \text { de } \\
\text { irradiação } & \end{array}$ & Intensidade do sinal \\
\hline $700 \mathrm{MHz}$ & $-84,681 \mathrm{~dB}$ \\
\hline $900 \mathrm{MHz}$ & $-89,413 \mathrm{~dB}$ \\
\hline $1,8 \mathrm{GHz}$ & $-89,088 \mathrm{~dB}$ \\
\hline $2,1 \mathrm{GHz}$ & $-78,972 \mathrm{~dB}$ \\
\hline
\end{tabular}

As frequências medidas foram especificadas a partir de pesquisas nos sites das principais operadoras de telefonia celular as quais demonstravam que as freqüências de $700 \mathrm{MHz}, \quad 900 \mathrm{MHz}, \quad 1800 \mathrm{MHz}$, $2100 \mathrm{MHz}$ eram as principais frequências de operação de trabalho das mesmas operadoras, assim estes valores foram inseridos no analisador de espectro para análise das intensidades proporcionais destas para o local.

Para a medição do sinal foi utilizada junto ao analisador de espectro, foi instalada uma antena tipo yagi-uda, a 2 metros de altura do solo, numa haste de ferro, que se encontrava no local, a uma distância de 30 metros da torre da antena mais próxima do equipamento de captação, amplificação e retransmissão do sinal, que se encontra nas coordenadas: Latitude $=-19.33667 /$ longitude $=$ 43.61806. O analisador de espectro foi ajustado para uma escala de $10 \mathrm{~dB}$ por divisão de forma que fosse possível verificar as características do gráfico obtido de formas nítidas.

No gráfico da Figura 8 observa-se a caracterização da onda e os dados obtidos na leitura do analisador de espectro.

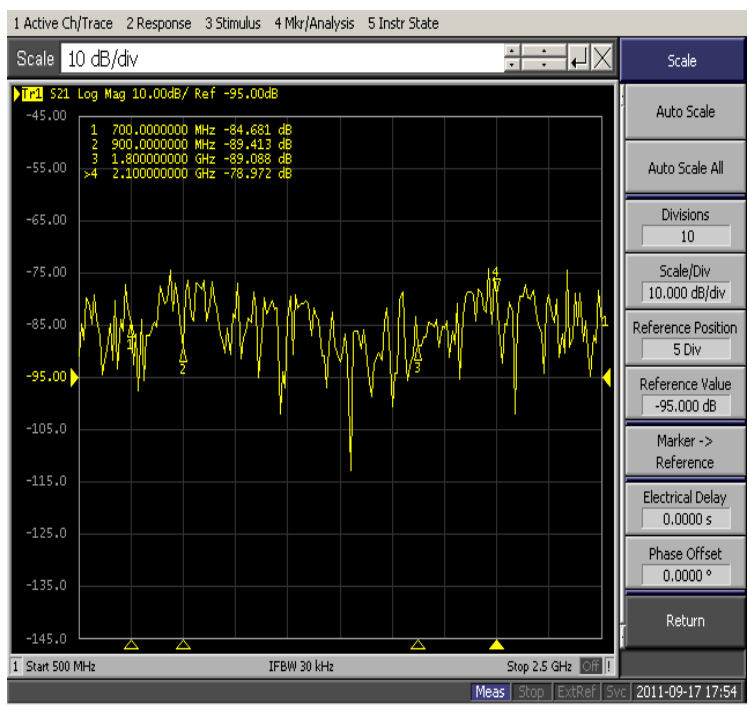

Figura 8 - Caracterização da onda medida da torre fonte das operadoras 
A figura 9 expõe a tela do analisador de espectro no qual se verifica a intensidade da onda na frequência de $2.1 \mathrm{GHz}$ oscilando em relação ao tempo. Esta oscilação pode ter ocorrido devido a interferências externas captadas pela antena, que pode ter sido causada pelos ventos ou umidade do ar do local ou até pela própria haste na qual a antena está fixada.

Verificou-se que os resultados das ondas obtidas eram semelhantes, nas diferentes freqüências, os quais variaram aproximadamente entre $-75 \mathrm{~dB}$ a $114 \mathrm{~dB}$.

O último parâmetro verificado na análise de local foi a intensidade dos sinais captados no local de instalação do equipamento. Este parâmetro é importante se verificar, pois a partir deste podem-se determinar as perdas que houve no transporte do sinal da torre até a área de estudo, além do quanto seria necessário amplificar o sinal para normalização do funcionamento dos equipamentos celulares no local.

Para medição foi utilizado o mesmo analisador de espectro das medições anteriores, onde foram medidas as intensidades dos sinais que chegavam à área de instalação do equipamento. Os resultados obtidos estão indicados na (Tabela 5).

Tabela 5 - Intensidades dos sinais medidos na área de instalação

\begin{tabular}{|c|c|}
\hline Freqüência de irradiação & Intensidade do sinal \\
\hline $700 \mathrm{MHz}$ & $-12,803 \mathrm{~dB}$ \\
\hline $900 \mathrm{MHz}$ & $-3,3634 \mathrm{~dB}$ \\
\hline $1,8 \mathrm{GHz}$ & $-779,03 \mathrm{mdb}$ \\
\hline $2,1 \mathrm{GHz}$ & $-983,56 \mathrm{mdB}$ \\
\hline
\end{tabular}

Para a medição do sinal foi utilizada junto ao analisador de espectro a mesma antena tipo yagi-uda da medição anterior, que foi instalada a 6 metros de altura do solo numa haste de ferro, que era um tubo de ferro doce de 1" polegada de espessuras, fixado ao chão nas coordenadas: Latitude $=-19.281403 /$ longitude $=-43.621158$. $O$ analisador de espectro foi ajustado para uma escala de $10 \mathrm{~dB}$ por divisão de forma que fosse possível verificar as características do gráfico obtido de formas nítidas.

No gráfico da (Figura 9), pode-se verificar a caracterização da onda, bem como os dados obtidos na leitura do analisador de espectro.

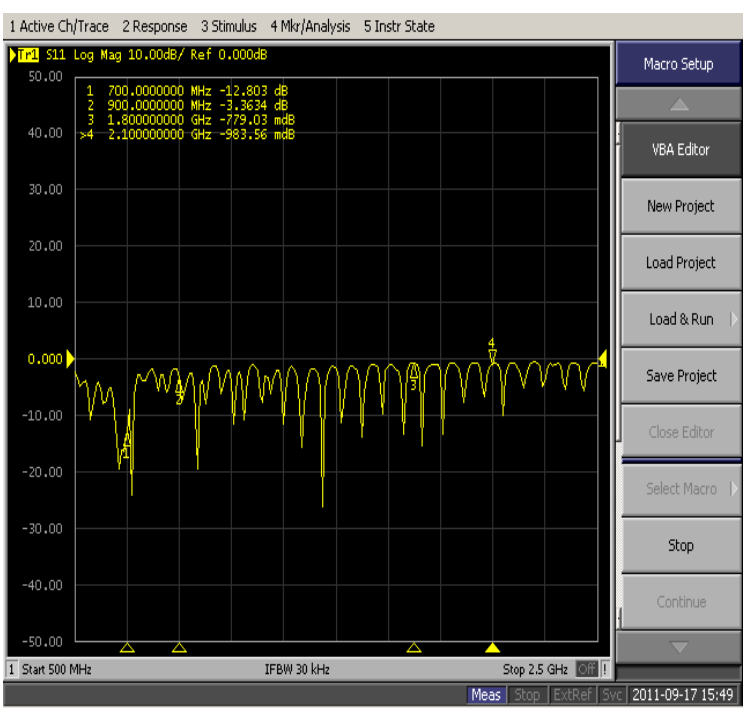

Figura 9 - Caracterização da onda medida na área de instalação

A figura 9 expõe a tela do analisador de espectro, no qual se verifica a intensidade da onda na frequência de $2.1 \mathrm{GHz}$ oscilando em relação ao tempo. Esta oscilação pode ter ocorrido devido a interferências externas captadas pela antena, que pode ter sido causada pelos ventos ou umidade do ar do local ou até pela própria haste, na qual a antena está fixada, como no caso anterior.

Verificou-se que os resultados, desta vez, foram bastante diferentes em relação aos resultados da análise anterior, onde os valores da intensidade dos sinais foram muito mais baixos, onde se concluiu que as perdas no trajeto dos sinais eram muito grandes. Outra informação verificada foi a diferença de intensidade dos sinais entre as frequências determinadas, isso ocorreu devido a especificação da 
antena ser de 700MHz. Observou-se que as intensidades medidas, mais próximas deste valor, eram mais altas. Assim, concluiu-se que para captação do sinal a antena deve ser especificada na frequência exata de trabalho do local, para obter uma alta eficiência de funcionamento do equipamento.

\subsection{DESENVOLVIMENTO DO PROTÓTIPO}

O equipamento desenvolvido tem a função de captar, amplificar e retransmitir os baixos níveis de sinais fornecidos pelas operadoras de telefonia móvel para região.

Assim, o primeiro passo de desenvolvimento do equipamento foi a parte de captação do sinal. Para captar o sinal. Para isto foi utilizada uma antena do tipo yagi-uda, que possui melhores rendimentos e possibilita longos alcances no uso para sinais de RF de baixas potências.

Como verificado na análise de local, a frequência de operação da antena deve ser de $1800 \mathrm{MHz}$. O alcance de captação que a antena deve ter, no mínimo, 7,5 km para captar sinais de todas as operadoras. Valor estipulado na medição do posicionamento entre o local de estudo e as torres mais próximas.

A antena deve ser específica para captação de sinais celulares de baixa potência e possuir alta eficiência de trabalho em condições adiversas do ambiente como ventos, umidade e outros. Ao pesquisar no mercado, verificou-se que a antena que melhor atendia às características estipuladas pelo projeto foi a antena da marca aquário, modelo CF-1817 de 17 dbi de ganho. Deve ser observado que para a especificação da antena foram levadas em consideração as suas principais características, a viabilidade econômica e viabilidade de aquisição (Figura 10).

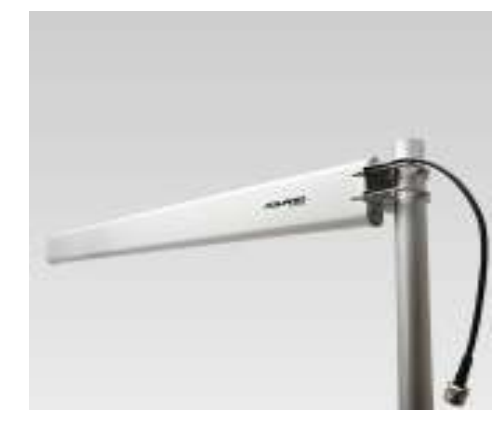

Figura 10 - Detalhe da antena Yagi-Uda

Fonte: JAQUARA, 2011.

A antena yagi-uda Aquário é uma antena do tipo direcional para recepção de sinal de celular, que possibilita fazer ou receber ligações normalmente em áreas de fraca cobertura das operadoras. Esta é utilizada por operadoras que trabalham na faixa de $1800 \mathrm{MHz}$, em instalações comerciais e residenciais, além de sítios, fazendas e casas de veraneio. Ideal também para escritórios, subsolos de prédios ou nas chamadas áreas de sombra das grandes e médias cidades. Indicada para áreas com frequentes quedas de chamada ou sinal fraco. Podendo também ser usada para acesso de internet via celular (GPRS / EDGE) ou para monitoramento de sistemas de segurança.

Os dados técnicos da antena da marca Aquário, modelo CF-1817 estão discriminados na Tabela 6.

No processo de amplificação do sinal RF, pode-se utilizar vários circuitos, nos quais são constituídos de amplificadores operacionais ou transistores de altas frequências, além de filtros eletrônicos, todos componentes são específicos para sistemas de rádio frequência. Assim considerou-se mais viável utilizar um amplificador bi direcional, disponível no mercado, com facilidade para a aquisição, preço acessível e que atende às funções determinadas pelo projeto. 
Tabela 6 - Parâmetros antena yagi-uda

\begin{tabular}{|c|c|}
\hline PARAMETROS & DESCRIÇÂO \\
\hline Freqüência & $1710 \mathrm{a} 1880 \mathrm{MHz}$ \\
\hline Ganho & $17 \mathrm{dbi}$ \\
\hline Alcance & até $40 \mathrm{~km}$ \\
\hline Relação F/B & $23 \mathrm{~dB}+-2 \mathrm{~dB}$ \\
\hline VSWR & $<1.5: 1$ \\
\hline Conector & N Fêmea \\
\hline Rejeição de Polarização & $>25 \mathrm{~dB}$ \\
\hline Potência Máxima & $10 \mathrm{~W}$ \\
\hline Impedância & $50 \mathrm{Ohms}$ \\
\hline Largura de faixa & $200 \mathrm{MHz}$ \\
\hline Resistência a ventos & $100 \mathrm{~km} / \mathrm{h}$ \\
\hline Ventos operacionais & $50 \mathrm{~km} / \mathrm{h}$ \\
\hline Peso & $740 \mathrm{~g}$ \\
\hline Dimensões & $930 \times 92 \times 75 \mathrm{~mm}$ \\
\hline Número de elementos & 20 \\
\hline
\end{tabular}

Fonte: JAQUARA, 2011.

Os principais dados a verificar na especificação deste equipamento são:

- sua capacidade de amplificação que necessita ser alta, pois os níveis de sinal do local estudado são muito baixos;

- área de cobertura que deve ser no mínimo de $1500 \mathrm{~m}^{2}$

- sua resistência de entrada deve ser de 50 ohms, que é igual à da antena yagi-uda, para permitir a máxima transferência de potência;

- ter freqüência de operação de $1800 \mathrm{MHz}$, além de facilidade de instalação e manutenção.

A partir de pesquisas e estudos constatou-se que o equipamento que melhor atenderia aos requisitos do trabalho, disponibilizando alto rendimento e de fácil aquisição no mercado, seria o repetidor amplificador Naccel RPT 1800mhz da fabricante Rede Camp (Figura 11). Este equipamento contém alta capacidade de amplificação de sinal celular e em conjunto com uma antena painel de alto ganho pode cobrir áreas de aproximadamente $2000 \mathrm{~m}^{2}$.

\section{Repetidor Celular 1800mhz}

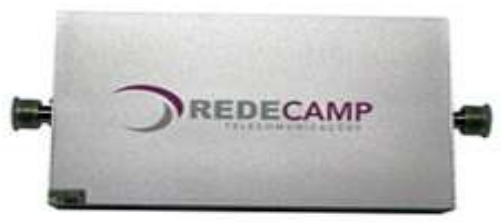

Operadoras que utilizam essa frequência *

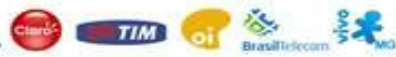

Figura 11 - Repetidor Celular indicado para o protótipo

Fonte: AUDCOM, 2011

As principais características que levaram os pesquisadores a indicarem o Repetidor amplificador modelo Naccel RPT 1800, estão apresentadas na (Tabela 7).

Finalizando o processo de desenvolvimento do equipamento resta verificar a parte de retransmissão do sinal.

Para retransmitir do sinal foi utilizada uma antena do tipo setorial painel, que possui excelentes rendimentos e possibilita grande densidade de sinal em áreas de cobertura para transmissão no uso de sinais de RF de baixas potências.

Como na antena anterior, a freqüência de operação continua a mesma para especificação ao qual foi verificado na análise de local. Assim a freqüência de operação da antena será de $1800 \mathrm{MHz}$. A mesma também deve obter impedâncias similares a da antena yagi-uda e ao amplificador repetidor que é de $50 \Omega$, para se obter a máxima transferência de potência entre os equipamentos estipulados e capacidade de cobertura de aproximadamente $1500 \mathrm{~m}^{2}$.

e-xacta, Belo Horizonte, v. 4, n. 3, p. 137-157. (2011). Editora UniBH Disponível em: www.unibh.br/revistas/exacta/ 
Tabela 7 - Especificação técnicas do repetidor celular $1800 \mathrm{MHz}$

\begin{tabular}{|c|c|}
\hline CARACTERISTICAS & DESCRIÇÃO \\
\hline FAIXA DE & UpLink: 1710/1785MHz \\
\hline FREQUENCIA & DownLink:1805/1880MHz \\
\hline \multirow[t]{2}{*}{ GANHO (dB) } & Uplink: Gap $\geq 55 \mathrm{~dB}$ \\
\hline & Downlink: $\mathrm{Gp} \geq 60 \mathrm{~dB}$ \\
\hline FAIXA DE GANHO & $M G C \geq 30$ \\
\hline AJUSTAVEL & \\
\hline POTÊNCIA DE SAIDA & $20 \mathrm{dBm}$ \\
\hline RIPPLE & $5 \mathrm{~dB}$ \\
\hline \multirow[t]{2}{*}{ REJEIÇÂO DE BANDA } & $(\mathrm{BW}-60 \mathrm{~dB}) \leq 42 \mathrm{MHz}$ \\
\hline & $(\mathrm{BW}-70 \mathrm{~dB}) \leq 45 \mathrm{MHz}$ \\
\hline IMPEDÂNCIA & $50 \Omega$ \\
\hline AREA DE & $2000 M^{2}$ \\
\hline \multicolumn{2}{|l|}{ CONVERGÊNCIA } \\
\hline PERDA DE RETORNO: & $\leq-8 \mathrm{~dB}$ \\
\hline FIGURA DE RUIDO & $\leq 8 \mathrm{~dB}$ \\
\hline ATENUAÇÃO DE & $\leq-40 \mathrm{dBc}$ \\
\hline \multirow{2}{*}{\multicolumn{2}{|c|}{$\begin{array}{l}\text { INTERMODULAÇÃO } \\
\qquad(P O=13 \mathrm{dbm}):\end{array}$}} \\
\hline & \\
\hline ATRASO DE & $\leq 0,5 \mu \mathrm{s}$ \\
\hline \multicolumn{2}{|l|}{ TRANSMISSÂO } \\
\hline TEMPERATURA & -30 a $50^{\circ} \mathrm{C}$ \\
\hline ALIMENTAÇÃO & 110/220 VAC \\
\hline COMPATIBILIDADE & ETS 300694-4 \\
\hline MAGNETICA & \\
\hline
\end{tabular}

Fonte: AUDCOM, 2011.

A partir dos dados, a antena que melhor atende às características estipuladas pelo projeto é a antena painel da marca celta, modelo CE-17018-10 de 7dbi de ganho, com capacidade de cobertura de 1000 a $1500 \mathrm{~m}^{2}$ (Figura 12). Levando em consideração que para estipulação da antena foi feita pelas suas principais características, facilidade de instalação, viabilidade econômica e viabilidade de aquisição.

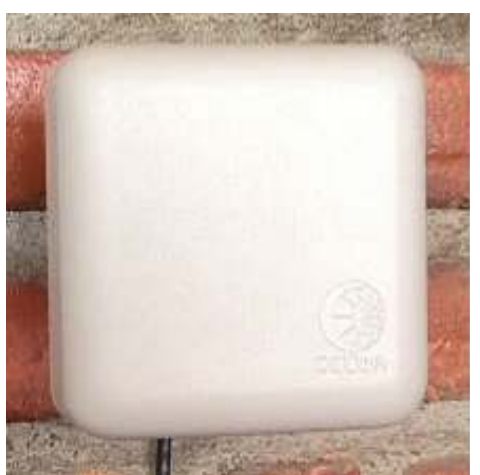

Figura 12 - Antena painel CE-17018-10

Fonte: CELTA-TELECOMUNICAÇÕES, 2011.

A antena setorial painel estipulada para o projeto tem as seguintes características (Tabela 8).

Tabela 8 - Principais características da antena painel Celta CE-17018-10

\begin{tabular}{|c|c|}
\hline CARACTERISTICAS & DESCRIÇÃO \\
\hline Ganho mínimo & $7 \mathrm{dBi} / 5 \mathrm{dBd}$ \\
\hline Faixa de Freqüência & $1710-1880 \mathrm{MHz}$ \\
\hline TOE & $<1,5$ \\
\hline Feixe de meia potência H & $90 \pm 5^{\circ}$ \\
\hline Feixe de meia potência E & $60 \pm 5^{\circ}$ \\
\hline Relação Frente/Costas & $>11 \mathrm{~dB}$ \\
\hline Potência máxima & $50 \mathrm{~W}$ \\
\hline Impedância & 50 Ohms \\
\hline Conector & TNC-fêmea \\
\hline Dimensões & $110 \times 110 \times 35(\mathrm{~mm})$ \\
\hline Peso com a ferragem & $270 \mathrm{~g}$ \\
\hline Peças de fixação & tubo de $\varnothing 1 "$ \\
\hline Materiais & $\mathrm{ABS}$ e aço inox \\
\hline Ajustes de azimute & $\pm 90^{\circ}$ \\
\hline Ajustes de elevação & $+60 /-45^{\circ}$ \\
\hline Área de Vento & $1,2 \mathrm{dm} 2$ \\
\hline Área de cobertura & $1000 \mathrm{a} 1500 \mathrm{~m}^{2}$ \\
\hline
\end{tabular}

Fonte: CELTATELECOMUNICAÇÕES, 2011.

\subsection{ACESSÓRIOS ADICIONAIS}

Para interligação dos equipamentos especificados anteriormente é necessária a utilização de cabos específicos para o sistema de comunicação RF.

Os cabos mais utilizados para estes sistemas são os cabos coaxiais que possuem alta capacidade de 
transmissão de dados e ainda possui uma alta isolação contra interferências internas de sinais.

Especificamente o cabo a ser utilizado para interligação dos equipamentos é o cabo coaxial RG213. A especificação deste modelo foi determinada por suas características de baixa atenuação de sinais em frequências altas o que é ideal ao projeto, mesmo este possuindo um custo um pouco elevado em relação a outros modelos de cabos coaxiais (Figura 13). Outro fator importante é o fato dos cabos RG-213 trabalharem na faixa de resistência de 50 ohms, valor equivalente a de todos os equipamentos especificados anteriormente.

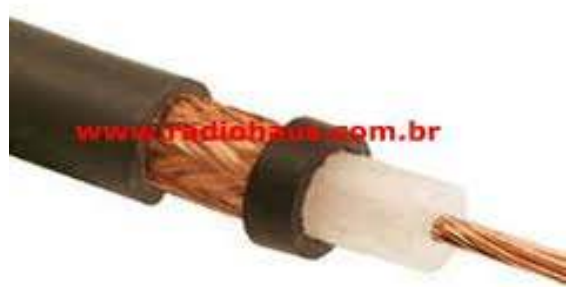

Figura 13 - Cabo coaxial RG-213

Fonte: RADIOHAUS, 2011.

Observação: é importante que todos os equipamentos do projeto tenham os mesmos valores de resistência para que haja um bom casamento de impedância entre os mesmo, assim diminuindo a taxa reflexão dos sinais transmitidos, obtém-se a máxima transferência de potência entre os equipamentos.

Os cabos coaxiais do tipo RG 213 têm como principais características as aplicações em antenas (fabricação de antenas com cabos montados), equipamentos de telecomunicações, equipamentos de rádio frequência. Suas especificações técnicas estão expostas na (Tabela 9).
Tabela 9 - Especificações técnicas do cabo coaxial RG-213

\begin{tabular}{|c|c|}
\hline \multicolumn{2}{|c|}{ CABO } \\
\hline Modelo & RG 213 \\
\hline Serie & 401002 \\
\hline Tipo de Cabo & Coaxial \\
\hline Condutor interno / Material & CNu2 \\
\hline $\begin{array}{l}\text { Diâmetro do condutor } \\
\text { interno } \mathrm{mm} \text { (in) }\end{array}$ & $2,26(0,09)$ \\
\hline Dielétrico / Material & $\mathrm{PE}$ \\
\hline $\begin{array}{l}\text { Diâmetro do condutor } \\
\text { Externo mm (in) }\end{array}$ & $8,11(0,32)$ \\
\hline Diâmetro da Capa mm (in) & $10,31(0,31)$ \\
\hline Diâmetro do dielétrico & $7,25(0,28)$ \\
\hline $\begin{array}{l}\text { Condutor externo / Material } \\
\text { (Blindagem) }\end{array}$ & TNu (96\%) \\
\hline \multicolumn{2}{|c|}{ ESPECIFICAÇÕES ELETRICAS } \\
\hline Impedância & $50 \mathrm{ohm}$ \\
\hline Velocidade de propagação & $66 \%$ \\
\hline Capacitância & $101 \mathrm{pF} / \mathrm{m}$ \\
\hline $\begin{array}{l}\text { Máxima Freqüência de } \\
\text { Operação }\end{array}$ & $3,0 \mathrm{GHz}$ \\
\hline $\begin{array}{l}\text { Resistência do Condutor } \\
\text { Externo }\end{array}$ & $5,8 \mathrm{ohm}$ \\
\hline Resistência de Blindagem & 4,1 ohm \\
\hline \multicolumn{2}{|c|}{$\begin{array}{c}\text { FREQUENCIA }(\mathrm{MHz}) \text { à } 20^{\circ} \mathrm{C} \\
\text { PERDAS dB/100m }\end{array}$} \\
\hline 1 & 0,6 \\
\hline 5 & 1,5 \\
\hline 10 & 2,0 \\
\hline 50 & 3,9 \\
\hline 100 & 6,8 \\
\hline 200 & 10,2 \\
\hline 450 & 15,5 \\
\hline 500 & 16,5 \\
\hline 1000 & 25,8 \\
\hline 1500 & 33,7 \\
\hline 1800 & 39 \\
\hline
\end{tabular}

Fonte: RADIOHAUS, 2011.

Para conexão dos cabos é necessária a utilização de 4 conectores próprios para cabos do tipo RG 213, sendo que destes, dois conectores tipo macho para interligação dos cabos as antenas e dois conectores tipo fêmea para interligação dos cabos junto ao repetidor amplificador.

Os modelos sendo escolhidos de acordo com suas características como modo de aplicação, impedâncias de trabalho e freqüências de operação.

e-xacta, Belo Horizonte, v. 4, n. 3, p. 137-157. (2011). Editora UniBH. Disponível em: www.unibh.br/revistas/exacta/ 
Primeiramente foi especificado o conector macho que é o Conector $\mathrm{N}$ modelo CNNM0007, que tem como descrição ser um conector Tipo $\mathrm{N}$ Macho de Junção para Cabo RG-213 (Figura 14).

\section{0}

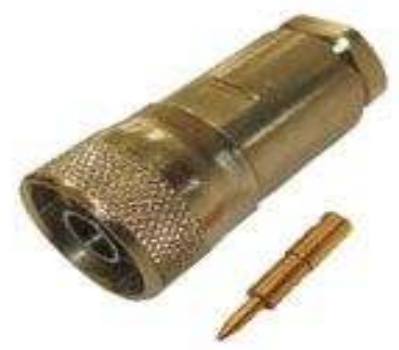

Figura 14 - Conector N macho modelo CNNM0007

Fonte: PROELETRONIC, 2011.

Este conector e muito utilizado em Conexão de cabos RG-213 em antenas, instrumentação, estações rádio base, celular, rádio de microondas, radar, radiodifusão, rádios e redes de computadores wireless.

A vantagem em utilizar os Conectores tipo $\mathrm{N}$ modelo CNNM0007 é sua ótima qualidade de fabricação, que é de acordo com as normas internacionais e sua fabricação é nacional e contem garantia de fábrica.

Sua principal especificação é trabalhar nas faixas de freqüências de $1 \mathrm{kHz}$ a $20 \mathrm{GHz}$ e seu material é o latão.

Os conectores da Série $\mathrm{N}$ com impedância de $50 \Omega$ são fabricados de acordo com as normas IEC 169-16, MIL-C-39012 e MIL-55339.

O conector fêmea especificado foi o Conector $\mathrm{N}$ modelo CNNF0005, que tem como descrição ser um conector Tipo N fêmea de Junção para Cabo RG-213 (Figura 15).
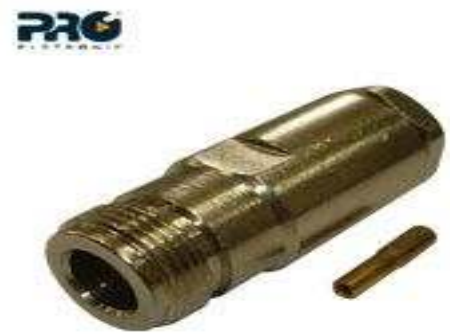

Figura 15 - Conector N fêmea modelo CNNF0005 Fonte: PROELETRONIC, 2011.

Este conector como o anterior também é muito utilizado em conexão de cabos RG-213 em antenas, instrumentação, estações radio base, celular, rádio de microondas, radar, radiodifusão, rádios e redes de computadores wireless. E sua vantagem é a ótima qualidade de fabricação, que é de acordo com as normas internacionais e sua fabricação é nacional e contem garantia de fábrica.

Sua principal especificação é trabalhar nas faixas de freqüências de $1 \mathrm{kHz}$ a $20 \mathrm{GHz}$, especifico para impedâncias de $50 \Omega$ e seu material é o latão.

De todos os equipamentos especificados no projeto o único que necessita de alimentação externa de energia elétrica é o amplificador repetidor de sinal, este necessita de uma alimentação de entrada de 110 á 220 VCA. Normalmente esta energia é fornecida pelas grandes concessionárias de energia elétrica e não são constantes em seus sistemas de distribuição de eletricidade. Estas energias fornecidas sofrem varias oscilações em seu fornecimento, como picos de energia e até falta da mesma devido às falhas nos sistemas de distribuição. Especificamente em áreas rurais, estes locais são de difíceis acessos e a manutenção do sistema chega a demorar horas para reabilitação da alimentação fornecida pela concessionária. 
Sabendo desta falha nos sistemas de alimentação de energia elétrica, foi detectada uma deficiência no equipamento desenvolvido, que é a dependência dos fornecedores de energia elétrica, pois acabando a energia fornecida pela concessionária automaticamente o equipamento desenvolvido se desenergiza e desliga, fazendo com que desapareça o sinal de celular.

Foi, então, verificada a necessidade de incluir mais um acessório no equipamento desenvolvido, o No-Break.

O No-Break é um sistema de alimentação considerado secundário de energia elétrica que entra em funcionamento, alimentando os dispositivos a ele ligados, quando há interrupção de energia elétrica primária. Estes são utilizados em aparelhos eletrônicos e sua alimentação consiste de um banco de baterias, que são carregadas enquanto a rede elétrica está funcionando corretamente.

Para especificação do No-Break utilizado no equipamento foi verificado alguns parâmetros que são essenciais para o projeto. Neste se verificou a necessidade de no mínimo de 10 Watts de potência de trabalho, que disponibilize tensão de saída na faixa de 110 a 220 volts, frequências entre $50 / 60 \mathrm{~Hz}$ e que tenha uma alta autonomia de tempo de funcionamento, além de possuir uma boa viabilidade econômica e fácil viabilidade de aquisição no mercado.

Assim o equipamento que melhor atendeu às características expostas pelo projeto foi o No-break da marca APC modelo PN: BE400G-BR (Figura 16).

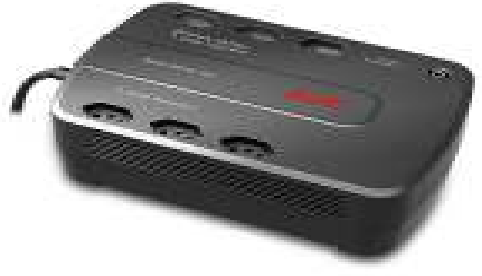

Figura 16 - No-break marca APC modelo PN: BE400G-BR

Fonte: NOBREAKAPC, 2011.

$O$ equipamento especificado pelos pesquisadores tem a seguinte descrição, Nobreak APC Back-UPS ES 6 Outlet 400VA 120V e suas especificações técnicas estão depostas na (Tabela 10).

Tabela 10 - Especificações técnicas do No-break marca APC modelo PN: BE400G-BR

\begin{tabular}{|c|c|}
\hline CARACTERISTICAS & DESCRIÇÃO \\
\hline Potência de Saída & 220 Watts/400 VA \\
\hline Tensão nominal de saída & $120 \mathrm{~V}$ \\
\hline Freqüência de Saída & $60 \mathrm{~Hz}$ \\
\hline Tipo de Forma de Onda & Senoidal \\
\hline $\begin{array}{c}\text { Proteção Necessária na } \\
\text { Corrente de Saída }\end{array}$ & $60 \mathrm{~Hz}$ \\
\hline Tensão nominal de entrada & $120 \mathrm{~V}$ \\
\hline Freqüência de entrada & $60 \mathrm{~Hz}+/-1 \mathrm{~Hz}$ \\
\hline Comprimento do Cabo & 1.52 metros \\
\hline $\begin{array}{c}\text { Intervalo de tensão de } \\
\text { entrada ajustável }\end{array}$ & $88-139 \mathrm{~V}$ \\
\hline Tipo de bateria & $\begin{array}{c}\text { Bateria selada } \\
\text { Chumbo - Acido }\end{array}$ \\
\hline
\end{tabular}

Fonte: NOBREAKAPC, 2011.

Uma das principais características de funcionamento do No-break APC modelo PN: BE400G-BR é seu tempo de autonomia de funcionamento em carga, o qual é importante para uma alta eficiência de funcionamento do equipamento projetado (Tabela 11). 
Tabela 11 - Autonomia de tempo em relação à carga no No-break

\begin{tabular}{|c|c|}
\hline $\begin{array}{c}\text { Tempo de Funcionamento } \\
\text { (min.) }\end{array}$ & Carga (Watt) \\
\hline 190,7 & 22 \\
\hline 69,9 & 50 \\
\hline 38,2 & 80 \\
\hline 21,9 & 120 \\
\hline 11,7 & 180 \\
\hline 8,2 & 220 \\
\hline
\end{tabular}

Fonte: NOBREAKAPC, 2011.

Como a carga em Watt do amplificador repetidor é de aproximadamente $10 \mathrm{~W}$, e sendo este valor é inferior a de 22 w que tem 190,7 minutos de funcionamento em carga, conclui-se que o tempo de autonomia do equipamento sem energia elétrica externa, no caso de um pico de energia é superior a 190,7 minutos o que equivale há aproximadamente 3 horas e 11 minutos.

\subsection{Posicionamento E condições de INSTALAÇÕES}

Os equipamentos especificados devem ser instalados observando as condições técnicas fornecidas pelos fabricantes.

Segundo a empresa GLOBALTELECOM, para instalação de antenas e repetidores amplificadores celulares devem-se verificar as condições básicas expressas a seguir. Escolher uma posição para antena externa direcional de forma a esta apontar na direção da torre (ERB), longe de rede elétrica ou qualquer obstáculos. A distância entre a antena de captação e a de transmissão de sinal deve ser no mínimo de 10 metros para evitar realimentação do sinal e interferências de uma antena a outra. A antena deve estar posicionada a uma altura ideal de forma a expandir o sinal por toda a área.
Assim foram definidos os posicionamentos das antenas e do amplificador de forma a ter uma alta eficiência de funcionamento dos equipamentos dispostos.

A primeira definição foi quanto ao posicionamento da antena yagi-uda, instalada externamente posicionada a 6 metros de altura do solo, onde foram constatadas menores atenuações dos sinais de telefonia celular emitidos pelas torres, que foi medido pelo analisador de espectro na análise de local. O amplificador, instalado a uma distância de 8 metros diagonais da antena externa e a 7 metros diagonais de distância da segunda antena. A antena de retransmissão de sinal, fixada em uma parede localizada na sala da casa, a uma altura de aproximadamente 2 metros junto à fonte No-Break, responsabilizando-se pela alimentação do equipamento. A segunda antena, a antena painel, instalada internamente no lado oposto da antena yagi, próximo ao teto da casa de forma que distribua o sinal para todos os cômodos da moradia, estando localizada a aproximadamente 12 metros diagonais de distância da antena yagi-uda e a 7 metros diagonais de distância do amplificador, a uma altura de 3 metros em ralação ao solo.

A antena painel também poderia ser instalada externamente de forma a expandir o sinal por toda a área do sitio, mas devido a grandes perdas, diminuição da eficiência dos equipamentos ocasionada pelas interferências de realimentação de sinais e a degradação dos equipamentos causada pela exposição ao tempo, optou-se pela instalação interna do equipamento.

As conexões dos cabos e conectores devem ser bem feitas, evitando perdas na transmissão dos sinais e, preferencialmente, as conexões externas devem ser isoladas com cabos de alta fusão para proteção contra umidades externas. 


\subsection{VIABILIDADE ECONÔMICA DO EQUIPAMENTO}

Como foi citado no desenvolvimento do trabalho, todos os equipamentos especificados no projeto foram determinados levando-se em consideração a eficiência, viabilidade econômica e viabilidade do produto no mercado. Assim foi realizada uma estimativa da viabilidade econômica total do equipamento desenvolvido, verificando os valores de todos os produtos expostos no mercado e seus fornecedores, que se encontra na Tabela 12.

Tabela 12 - Viabilidade econômica do equipamento projetado

\begin{tabular}{|c|c|c|c|c|}
\hline EQUIPAMENTO & QTS & $\begin{array}{c}\text { VALOR } \\
\text { UNITARIO }\end{array}$ & $\begin{array}{c}\text { VALOR } \\
\text { INTEGRAL }\end{array}$ & FORNECEDOR \\
\hline $\begin{array}{c}\text { Antena Yagi - } \\
\text { Uda }\end{array}$ & $01 \mathrm{PÇS}$ & $R \$ 129,00$ & $R \$ 129,00$ & JAGUARA \\
\hline $\begin{array}{c}\text { Amplificador } \\
\text { repetidor } \\
\text { Antena Painel }\end{array}$ & $01 \mathrm{PÇS}$ & $\begin{array}{c}R \$ \\
1688,00 \\
R \$ 149,00\end{array}$ & $\begin{array}{c}R \$ \\
1688,00 \\
R \$ 149,00\end{array}$ & $\begin{array}{c}\text { AUDCOM } \\
\text { TELECOM } \\
\text { CELTA } \\
\text { TELECOM }\end{array}$ \\
\hline $\begin{array}{c}\text { Cabos Coaxiais } \\
\text { RG }-213\end{array}$ & $\begin{array}{c}20 \\
\text { METROS }\end{array}$ & $\begin{array}{l}R \$ 10,98 \\
\text { (o metro) }\end{array}$ & $R \$ 219,60$ & RADIOHAUS \\
\hline $\begin{array}{c}\text { Conector Macho } \\
\text { RG }-213\end{array}$ & $02 \mathrm{PÇS}$ & $R \$ 7,20$ & $\mathrm{R} \$ 14,40$ & SHOP MANIA \\
\hline $\begin{array}{c}\text { Conector fêmea } \\
\text { RG -213 }\end{array}$ & $02 \mathrm{PÇS}$ & $R \$ 8,10$ & $R \$ 16,20$ & SHOP MANIA \\
\hline No-Break $220 \mathrm{w}$ & $01 \mathrm{PÇS}$ & $\mathrm{R} \$ 175,13$ & $\mathrm{R} \$ 175,13$ & $\begin{array}{c}\text { KS TEC } \\
\text { TECNOLOGIA }\end{array}$ \\
\hline \multicolumn{5}{|c|}{ VALOR TOTAL: R\$ 2391,33 } \\
\hline
\end{tabular}

A partir dos dados obtidos e expostos na Tabela 12 foi possível averiguar a viabilidade econômica do equipamento, lembrando que os valores são aproximados, já que os valores dos produtos estipulados variam conforme cada fornecedor e a data de cotação. A cotação total estimada para o equipamento foi de $\mathrm{R} \$ 2391,33$ mesmo este valor sendo, analisado isoladamente, considerado relativamente alto, ao verificar a relação de custo/ beneficio, ele é considerado viável e acessível para implementação e instalação do projeto.

\section{ConCLUSÃo}

Como foi discutido no trabalho, a instalação de antenas de celulares para meios rurais é essencial para a comunidade, pois proporciona aos moradores o acesso à comunicação.

As antenas, colocadas no meio rural, têm como objetivo amplificar e retransmitir o sinal que vem das operadoras de celular, proporcionando o acesso à telefonia celular para pessoas de regiões isoladas.

A região onde foi feito o estudo de campo é uma região composta de várias diversidades ecológicas como serras, matas, rios e pedreiras. Isso faz com que o sinal tenha dificuldades de chegar até a região desejada.

Ao final do projeto verificou que ele é acessível para a instalação, apesar de ter o custo elevado, mas comparando o custo ao benefício, compensa a instalação.

A pesquisa servirá de auxílio para todos os profissionais que atuarem na área de Antenas, pois a metodologia utilizada pode contribuir na colocação das antenas, gerando rapidez e precisão técnica.

Os dados apresentados foram frutos de um processo de pesquisa detalhada sobre antenas e instalações telefônicas. Com a elaboração do trabalho houve um grande aprendizado, no qual foi visto tudo o que é necessário para montagem de antenas no meio rural.

\section{CONSIDERAÇÕES FINAIS}

Para trabalhos futuros é recomendada a continuidade o desenvolvimento do protótipo, sempre buscando melhor eficiência e qualidade do produto a desenvolver, lembrando que o mesmo pode ser readaptado para outras regiões, que também tenha problemas com disponibilidade de sinal celular. 
A viabilidade desse protótipo ficou com o custo alto, devido a pouca disponibilidade dos equipamentos no mercado nacional. Para a redução deste custo, é sugerido para pesquisas futuras, ao invés de cotar os equipamentos, projetá-los, o que aumentaria mais a viável econômica do equipamento.

\section{AgRADECIMENTOS}

Os autores agradecem, inicialmente, a Deus que iluminou os nossos caminhos durante toda esta caminhada.

Aos nossos pais, pela dedicação e apoio durante toda esta jornada acadêmica.
À Instituição UNI-BH pelo incentivo, apoio e infraestrutura para o desenvolvimento e conclusão deste projeto.

Um agradecimento especial às professoras Vanessa Cristina Lopes Santos e Sílvia Calmon de Albuquerque por todo o esforço e dedicação para o desenvolvimento deste trabalho.

Um muito obrigado a co-orientadora Prof. ${ }^{a}$ Arlete Vieira da Silva pelo aprendizado e dedicação por esses meses de trabalho juntos, e também pela sua compreensão e profissionalismo.

Um agradecimento a todos os professores, alunos e técnicos da Instituição UNI-BH, em especialmente aos que estão ligados ao curso de Engenharia Elétrica.

\section{REFERÊNCIAS}

ALENCAR, Marcelo Sampaio de. Sistemas de comunicações. São Paulo: Erica LTDA, 2001. 298 p. BERNAL, Paulo Sergio Milano. Comunicações movéis. São Paulo: Erica LTDA, 2004.204 p.

AUDCOM. Repetidor 1800MHz. Disponível em: www.audcom.com.br/loja/marca/Redecamp.html Acesso em: 16 out. 2011.

BALANIS, Constantine A. Teoria de Antenas. Rio de Janeiro: LTC, 2005. 345 p.

BARRADAS, Ovídio César Machado. Você e as telecomunicações. São Paulo: Interciência, 1995. 278 p. CELTA-TELECOMUNICAÇÕES. Antena painel.
Disponível em: telecomunicacoes.com.br/catalog/product_info.php?pr oducts_id=28 - Acesso em: 16 out. 2011.

CLARO. Roamings. Disponivel em: http://www.claro.com.br/portal/coberturanacional Acesso em: 10 set. 2011.

COBERTURACELULAR. Disposição das Torres Celulares. Disponível em: http:// www.coberturacelular.com.br - Acesso em: 3 out. 2011.
GIL, Antonio Carlos. Como Elaborar Projetos de Pesquisa. São Paulo: Atlas, 2010. 184 p.

GLOBALTELECOM. Instalação de antenas e repetidores. Disponível em: http://globaltelecom.com.br/ - Acesso em: 19 out. 2011.

GOMES, Alcides Tadeu. Telecomunicações transmissão e recepção. São Paulo: Erica LTDA, 2004. 415 p.

GUIASERRADOCIPO. Mapa da Regional. Disponível em: http://www.guiaserradocipo.com.br - Acesso em: 18 out. 2011.

JAQUARA. Antena Yagi-uda aquário CF1817. Disponível em: http://www.jaguara.com.br/ - Acesso em: 16 out. 2011.

KRAUS, John Daniel. Antenas. São Paulo: Guanabara, 1983. 516 p.

MORIMOTO, Carlos E. - Guia do Hardware - Artigo: Redes wireless, parte 4: Antenas e conectores (Janeiro de 2008). Disponível em: http://www.hardware.com.br/tutoriais/alcance-antenasconectores-potencia/pagina3.html - Acesso em: 16 maio 2011. 
NOBREAKAPC. No-Break BE400G. Disponível em: http://nobreakapc.com.br/produtos/mostrar/218/

BE400G-

RR/nobreak_apc_back_ups_es_6_outlet_400va_120v - Acesso em: 19 out. 2011.

OI. Roamings. Disponivel em: http://oimovel.oi.com.br/portal/site/OiMovel/menuitem. - Acesso em: 10 set. 2011.

PROELETRONIC. Conectores macho e fêmeas para cabo RG 213. Disponível em http://www.proeletronic.com.br/ produtos/conecto r-nrg213-juncao-macho/126/45 - Acesso em: 19 out. 2011.

RADIOHAUS. Cabo coaxial RG-213 - Disponível em: http://www.radiohaus.com.br/produto.php?prod=638 Acesso em: 19 out. 2011.
SERRADOCIPO. Informações Gerais da Região. Disponível em:

http://www.serradocipo.com/infogerais - Acesso em: 1 out. 2011.

SHOPMANIA. Produtos eletrônicos. Disponivel em: http://www.shopmania.com.br/ - Acesso em: 22 out. 2011.

TIM. Roamings. Disponível em: http://www.tim.com.br/portal/site/PortalWeb/menuitem - Acesso em: 10 SET. 2011.

VIVO. Roamings. Disponivel em: http://www.vivo.com.br/portal/para-voce-coberturavivo.php - Acesso em: 10 set. 2011. 